\title{
Evaluation of the relationship between cognitive impairment and suboptimal health status in a northern Chinese population: a cross-sectional study
}

\author{
Guoyong Ding ${ }^{1 *}$, Xuan Zhao ${ }^{1 *}$, Youxin Wang ${ }^{2 *}$, Daiyu \\ Song ${ }^{1}$, Dongzhen Chen ${ }^{1}$, Yang Deng ${ }^{1}$, Weijia Xing ${ }^{1}$, \\ Hualei Dong ${ }^{3}$, Yong Zhou ${ }^{4}$, Dong $\mathrm{Li}^{1}$, Haifeng Hou ${ }^{1}$ \\ ${ }^{1}$ School of Public Health, Shandong First Medical University \& \\ Shandong Academy of Medical Sciences, Taian, Shandong \\ Province, China \\ ${ }^{2}$ Beijing Key Laboratory of Clinical Epidemiology, School of \\ Public Health, Capital Medical University, Beijing, China \\ ${ }^{3}$ Taishan Hospital of Shandong Province, Taian, Shandong \\ Province, China \\ ${ }^{4}$ Eye Hospital, Wenzhou Medical University, Wenzhou, \\ Zhejiang Province, China \\ * Equal authorship.
}

\section{Correspondence to:}

Haifeng Hou

Department of Epidemiology

Shandong First Medical University

\& Shandong Academy of Medical Sciences

619 Changcheng Road

Taian 271016

Shandong Province

China

hfhou@163.com

Yong Zhou

Institute of Systemic Diseases

and Ophthalmology

Eye Hospital

Wenzhou Medical University

270 Xueyuanxi Road

Wenzhou 325027

Zhejiang Province

China

yongzhou78214@163.com

Dong Li

School of Public Health

Shandong First Medical University

\& Shandong Academy of Medical Sciences

619 Changcheng Road

Taian 271016

Shandong Province

China

tsmcdongli@163.com
Background Suboptimal health status (SHS) is an intermediate health status between ideal health and illness. As a determinant of cardiovascular disease and stroke, SHS is hypothesized to be associated with the development of cognitive impairment and dementia. This study aimed to investigate whether individuals with SHS have poor cognitive ability based on a community-based cohort in northern Chinese population.

Methods 3524 participants who were enrolled in Jidong cohort 2015 in Tangshan City were investigated in this study. Cognitive function was measured with the Mini-Mental State Examination (MMSE). SHS level was evaluated using a self-reporting Suboptimal Health Status Questionnaire-25 (SHSQ-25). The relationship between SHS and cognitive function was analyzed with logistic regression analysis, by which odds ratio (OR) and 95\% confidence interval (CI) were calculated.

Results The prevalence of cognitive impairment was 3.4\% (121/3524) in our study, with the prevalence rates of 1.9\% (34/1750) among men and $4.9 \%$ $(87 / 1774)$ in women. The medians of total score of MMSE were 28 (interquartile range $(I Q R)=27-29)$ in the SHS group, and 29 (IQR=27-30) in the ideal health group. Logistic regression analysis showed that SHS was significantly correlated with cognitive impairment (adjusted OR $=2.936,95 \% \mathrm{CI}=1.428$ 6.033). With regard to gender, the OR was 5.067 (95\% CI $=1.346-19.068)$ in men, which was higher than that in women $(\mathrm{OR}=2.324,95 \% \mathrm{CI}=1.130$ 4.779).

Conclusions SHS might be a risk factor for cognitive function in northern Chinese population. Early screening of SHS individuals, as well as urgent treatment of SHS might contribute to the prevention of cognitive impairment. 
Cognitive impairment is the intermediate stage between the intact cognitive functioning and early clinical dementia [1]. The incidences of cognitive impairment and dementia have been increasing worldwide [2]. And the number of new diagnosed dementia is 7.7 million each year, and will be 75.6 million by 2030[2]. In the Asia-Pacific region, the number of dementia patients is expected to increase from 27 million in 2015 to 70 million in 2050 [3]. With the acceleration of ageing of the population process, cognitive impairment has become an increasing challenge for health care systems in China, where the corresponding caregivers are urgently needed [4]. As no medications can effectively reverse the progression of dementia, identifying the modifiable risk factors, as well as lessening the exposure to these factors is crucial for the reduction of the burdens.

Suboptimal health status (SHS) is an intermediate health status between ideal health and illness [5]. As a reversible subclinical stage, SHS was described as perceptible discomfort symptoms, such as health complaint, self-reported weakness, chronic fatigue, non-specific pain and psychological symptom [6]. Advances have been acquired for measurement and evaluation of SHS in these years. Suboptimal Health Status Questionnaire-25 (SHSQ-25) is the most widely used scale for measurement of SHS [7,8], which has been used in Africans, Asians and Caucasians [5]. Accumulating evidences indicated the associations between SHS and a wide range of diseases including mental disorders $[9,10]$, psychosocial stress [11], obsessive-compulsive symptom and depression symptom [12], hypercholesterolemia [13], overweight and obesity [14], stroke [15,16], type II diabetes and cardiovascular disease [17]. All these diseases are related to the development of dementia. Therefore, we conducted this study to estimate the prevalence rates of cognitive impairment among a northern Chinese population, and investigated whether cognitive impairment was associated with SHS.

\section{METHODS}

\section{Study design and participants}

This study was approved by the Ethics Committee of Shandong First Medical University and the Ethic Committee of Workers' Hospital of Jidong Oilfield of Petro China (No. 01-2013). The participants in this study were recruited from Jidong cognitive impairment cohort study (CICS) in Tangshan City in 2015. CICS is a community-based, prospective, long-term observational cohort study to evaluate potential risk factors and prognosis of cognitive impairment [18]. Tangshan is located in the central part of the Bohai Rim, adjacent to Beijing and Tianjin.

The inclusion criteria of the study were: 1) age >40 years; 2) local Han population; 3) complete basic information available; 4) signed informed consent. A total of 6656 people agreed to participate in the questionnaire survey, among which 3128 individuals were under 40 years old, three did not complete the Mini-Mental State Examination (MMSE) questionnaire and one did not complete the SHSQ-25 questionnaire. Finally, we included 3524 participants in this study (Figure 1).

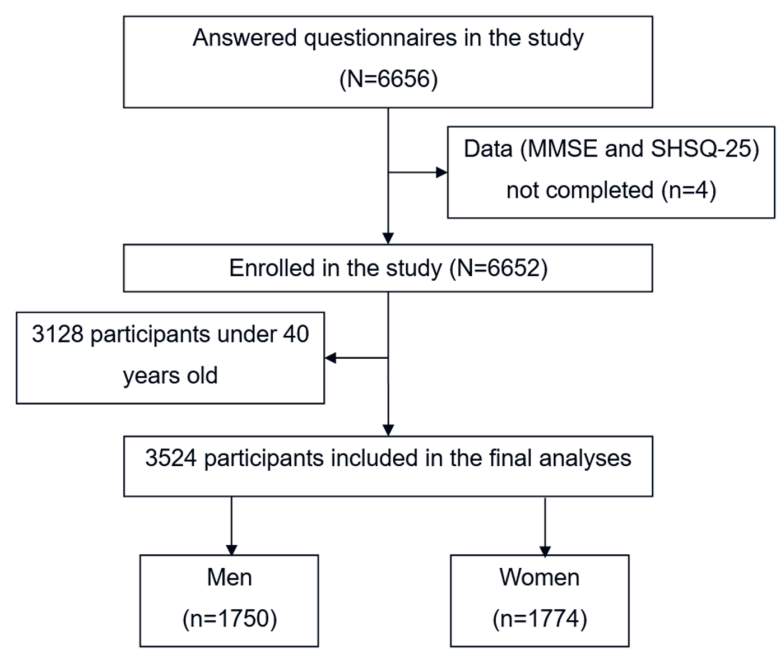

Figure 1. Selection procedures of the study. MMSE Mini-Mental State Examination; SHSQ-25 - Suboptimal Health Status Questionnaire-25.

\section{Anthropometric variables and clinical data}

Data were collected via a single visit by experienced physicians and trained nurses, where a standard questionnaire was used by a face-to-face interview. We collected the following information of the participants: 1) personal information (gender, age, educational level, living status, body mass index (the ratio of weight, $\mathrm{kg}$ / height squared, $\mathrm{m}^{2}$ ), per-capita living space, number of family members, family environment and family hygiene), 2) disease history (hypertension, diabetes, hyperlipemia, coronary heart disease (CHD), fatty liver, autoimmune disease, respiratory disease, chronic gastritis, gastric ulcer and duodenal ulcer), 3) lifestyle (smoking, drinking and staying up late), and 4) dietary habits.

\section{Cognitive impairment evaluation}

Cognitive function was measured with the MMSE [19], which consists of 30 items that evaluate five cognitive dimensions: 
1) orientation to time and place (10 points), 2) word registration (3 points), 3) attention and calculation (5 points), 4) recall (3 points) and 5) language (containing visual construction, 9 points). The scores of MMSE range from 0 to 30, the higher scores indicate better cognitive function. The MMSE scale has a sensitivity above $88.3 \%$ and a specificity of $87 \%$ with a cut-off point of 24 for detecting cognitive impairment in patients with neurodegeneration $[20,21]$. In this study, cognitive impairment was defined as: a score $\leq 17$ for illiterates; a score $\leq 20$ for primary school graduates ( $\geq 6$ years of education); and a score $\leq 24$ for junior school graduates or above ( $\geq 9$ years of education) $[22,23]$.

\section{SHS evaluation}

The condition of SHS was measure by the questionnaire SHSQ-25 (Table S1 in the Online Supplementary Document). The SHSQ-25 includes 25 items on five dimensions: 1) fatigue, 2) cardiovascular system, 3) digestive tract, 4) immune system and 5) mental health [12,17]. According to how often respondents experienced symptoms in the previous three months, each item was presented in a specific form on a Likert scale on a five-point scale. The raw scores of 1-5 on the questionnaire were recorded as 0-4. The total score of SHSQ-25 of each subject was obtained by summing the scores of the 25 items. The conditions of participants were stratified into two classifications: ideal health (with summed score $<35$ ) and suboptimal health status (with summed score $\geq 35$ ) $[17,19]$. The SHSQ-25 has good individual internal consistency with the Cronbach's $\alpha$ coefficient was 0.91 [5]. Studies have showed that the SHSQ-25 is a reliable and valid instrument for measuring sub-health status in Chinese population [24,25].

\section{Statistical analysis}

All the statistical analyses were performed by SPSS (version 25.0, IBM, New York, USA). Qualitative data were presented as a rate or percentage. The normality of continuous variables was conducted by using the Shapiro-Wilk test. Continuous variables of normality distributions were expressed as mean \pm standard deviation (SD). Median and interquartile range (IQR) were used for non-normally distributed data. The differences between the healthy group and SHS group were tested by test for normally distributed data and Wilcoxon rank sum test for non-normally distributed or graded variables, or chi-square $\left(\chi^{2}\right)$ test (discrete variables). The Cochran Armitage trend test was adopted to analyze the linear trend between cognitive impairment and educational level. Multivariate logistic regression was used to examine the relationship between cognitive impairment and SHS, where odds ratio (OR) and 95\% confidence interval (CI) were calculated. $P$ value of less than 0.05 was considered statistically significant.

\section{RESULTS}

\section{Characteristics of participants}

Among 3524 participants (mean age $54.57 \pm 8.74$ years) included in this study, 1750 (49.7\%) were men (mean age $54.88 \pm 8.98$ years) and 1774 (50.3\%) were women (mean age $54.27 \pm 8.48$ years). All

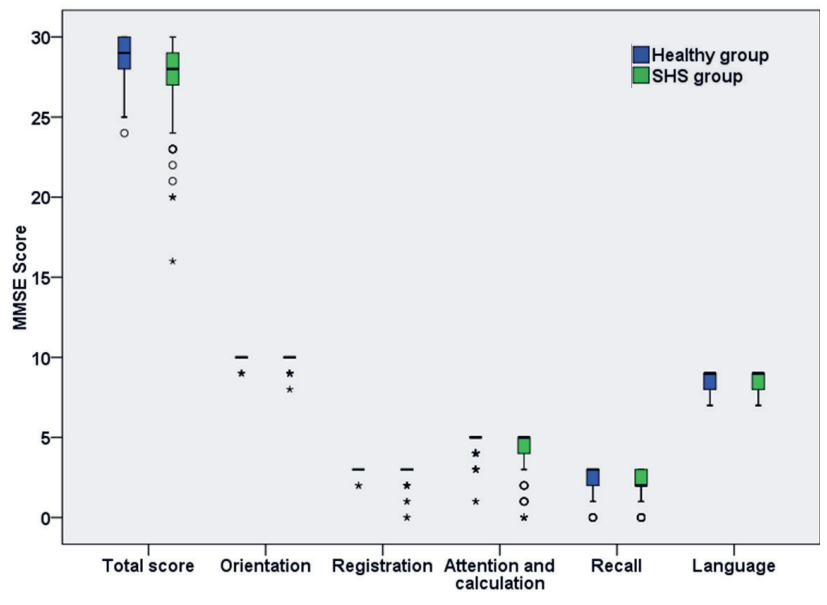

Figure 2. Box plot of Mini-Mental State Examination scores in the healthy and suboptimal healthy status groups. The data were expressed as minimum, $\mathrm{P}_{25}$, median, $\mathrm{P}_{75}$, maximum, outlier and extreme. SHS - suboptimal healthy status. the participants were classified into two groups on the basis of the SHSQ-25 scores: healthy group $(n=3381)$ and SHS group ( $n=143$ ). The characteristics of the participants in each group are presented in Table 1. The differences of SHS prevalence were not significant between age-groups. In addition, education level, living status, BMI, per-capita living space, family environment, and family hygiene classifications were not related to SHS prevalence. While, the prevalence of SHS among women was significantly higher than that among men $(P<0.001)$. And the prevalence among the participants lived alone was $7.2 \%$, which was significantly higher than participants lived with his/her families $(P=0.020)$.

\section{The prevalence of cognitive impairment}

The MMSE score in the healthy and SHS groups were shown in Figure 2 and Table S2 in the Online Supplementary Document. The median of total score of MMSE was 29 (IQR: 27-30) in the healthy group and 28 (IQR: 27-29) in the SHS 
Table 1. Demographic characteristics of study participants among healthy and suboptimal health status groups.

\begin{tabular}{|c|c|c|c|c|c|}
\hline Сharacteristics & ТотAL & Heatihy & SHS & $x^{2} / T$ & $\mathbf{P}$ \\
\hline Age (years)* & $54.57 \pm 8.74$ & $54.52 \pm 8.75$ & $55.72 \pm 8.30$ & 1.607 & 0.108 \\
\hline BMI $\left(\mathrm{kg} / \mathrm{m}^{2}\right)^{*}$ & $24.94 \pm 3.29$ & $24.96 \pm 3.28$ & $24.46 \pm 3.62$ & 1.751 & 0.080 \\
\hline \multicolumn{6}{|l|}{ Gender: } \\
\hline Male (n, \%) & 1750 & $1707(97.5)$ & $43(2.5)$ & 22.880 & $<0.001$ \\
\hline Female (n, \%) & 1774 & $1674(94.5)$ & $100(5.6)$ & & \\
\hline \multicolumn{6}{|l|}{ Education: } \\
\hline Illiterate (n, \%) & 84 & $78(92.9)$ & $6(7.1)$ & 6.802 & 0.078 \\
\hline Primary (n, \%) & 296 & $283(95.6)$ & $13(4.4)$ & & \\
\hline Middle (n, \%) & 1874 & $1788(95.4)$ & $86(4.6)$ & & \\
\hline College (n, \%) & 1251 & $1213(97.0)$ & $38(3.0)$ & & \\
\hline Living alone (n, \%) & 98 & $93(94.9)$ & $5(5.1)$ & 0.323 & 0.570 \\
\hline \multicolumn{6}{|c|}{ Per-capita living space $\left(\mathrm{m}^{2}\right)$ : } \\
\hline$\leq 30(\mathrm{n}, \%)$ & 792 & $761(96.1)$ & $31(3.9)$ & 0.688 & 0.709 \\
\hline $30-59(n, \%)$ & 1430 & $1376(96.2)$ & $54(3.8)$ & & \\
\hline$\geq 60(\mathrm{n}, \%)$ & 1300 & $1243(95.6)$ & $57(4.4)$ & & \\
\hline \multicolumn{6}{|c|}{ N. of family members: } \\
\hline one $(\mathrm{n}, \%)$ & 138 & $128(92.8)$ & $10(7.2)$ & 7.862 & 0.020 \\
\hline two - four (n, \%) & 3198 & 3067 (95.9) & $131(4.1)$ & & \\
\hline Five or more (n, \%) & 186 & $184(98.9)$ & $2(1.1)$ & & \\
\hline \multicolumn{6}{|l|}{ Family hygiene: } \\
\hline Very Good (n, \%) & 2397 & $2306(96.2)$ & $91(3.8)$ & 1.188 & 0.552 \\
\hline Good (n, \%) & 1110 & $1060(95.5)$ & $50(4.5)$ & & \\
\hline Poor (n, \%) & 16 & $15(93.8)$ & $1(6.3)$ & & \\
\hline
\end{tabular}

SHS - suboptimal health status, BMI - body mass index

*Data were expressed as mean and standard deviation.

group. Compared with health participants, SHS individuals had lower cognitive function in overall level $(P=0.001)$, word registration domain $(P=0.010)$, and attention and calculation domain $(P=0.001)$.

The prevalence of cognitive impairment was 3.4\% (121/3524) in this study, with 1.9\% (34/1750) among men and 4.9\% (87/1774) among women. As shown in Table 2, the prevalence rates of cognitive impairment had a significant difference between age groups $(P<0.001)$. The prevalence of cognitive impairment was relatively high in people over the age of 61 . The prevalence rate of cognitive impairment was highest in the participants with illiterate (40.5\%). The trend that the prevalence of cognitive impairment decreased with the increase of education level was also observed in both men and women groups (Total: $P<0.001$; Men: $P<0.001$; Women: $P<0.001)$. The prevalence of cognitive impairment for lived alone individuals (9.2\%) was higher than that of not lived alone individuals $(3.3 \%, P=0.004)$. For the classifications of per-capita living space, the prevalence rates of cognitive impairment were statistically different between groups (Table S3 in the Online Supplementary Document, $P=0.014$ ). No significant differences were found for subgroup analyses on BMI, number of family members, family environment and family hygiene (Table S3 in the Online Supplementary Document).

\section{The relationship of cognitive impairment with lifestyles and dietary habits}

As shown in Table 3 and Table S4 in the Online Supplementary Document, the prevalence of cognitive impairment was significantly associated with smoking habit $(P=0.018)$, drinking $(P<0.001)$, fried food $(P=0.001)$ and spicy food intakes $(P=0.042)$, and staying up late $(P=0.025)$. With regard to gender, cognitive impairment was significantly associated with fried food $(P<0.001)$, spicy food $(P=0.013)$, pickled food $(P<0.001)$ and bacon intakes $(P<0.001)$ among men. While only staying up late was significantly associated with cognitive impairment among women $(P=0.021)$.

\section{The relationship between cognitive impairment and disease history}

Figure 3 shows percentages of cognitive impairment among participants with or without a history of disease. The percentages of cognitive impairment among total participants with hypertension ( $5.0 \%$ vs $2.5 \%$ ), diabetes ( $5.9 \%$ vs $3.0 \%)$ and autoimmune $(5.3 \%$ vs $3.2 \%$ ) were significantly higher than that among participants without these diseases (all $\mathrm{P}<0.05$ ). In male participants, the percentages of cognitive impairment among participants with CHD (11.8\% vs $1.8 \%)$ and autoimmune (4.7\% vs $1.6 \%)$ than that among 
Table 2. Prevalence rates of cognitive impairment in the subgroups of demographics*

\begin{tabular}{|c|c|c|c|c|}
\hline Suberoups & No. & Cases & MaLE CASES & FEMALE CASES \\
\hline \multicolumn{5}{|l|}{ Age (years): } \\
\hline $41-45(n, \%)$ & 655 & $5(0.8)^{a}$ & $2(0.6)^{a}$ & $3(0.9)^{a}$ \\
\hline $46-50(n, \%)$ & 719 & $7(1.0)^{\mathrm{a}}$ & $2(0.6)^{a}$ & $5(1.4)^{\mathrm{a}}$ \\
\hline $51-55(n, \%)$ & 541 & $9(1.7)^{\mathrm{a}, \mathrm{b}}$ & $2(0.8)^{a}$ & $7(2.5)^{\mathrm{a}, \mathrm{b}}$ \\
\hline $56-60(n, \%)$ & 517 & $22(4.3)^{b, c}$ & $5(2.2)^{\mathrm{a}, \mathrm{b}}$ & $17(5.9)^{\mathrm{b}, \mathrm{c}}$ \\
\hline 61-65 (n, \%) & 695 & $41(5.9)^{c, d}$ & $8(2.2)^{a, b}$ & $33(9.9)^{c}$ \\
\hline$\geq 66(\mathrm{n}, \%)$ & 397 & $37(9.3)^{\mathrm{d}}$ & $15(6.7)^{\mathrm{b}}$ & $22(12.6)^{c}$ \\
\hline$P$-value & & $<0.001$ & $<0.001$ & $<0.001$ \\
\hline \multicolumn{5}{|l|}{ Education: $\dagger$} \\
\hline Illiterate (n, \%) & 84 & $34(40.5)^{a}$ & $5(26.3)^{a}$ & $29(44.6)^{a}$ \\
\hline Primary (n, \%) & 296 & $40(13.5)^{b}$ & $11(9.6)^{\mathrm{a}}$ & $29(16.0)^{\mathrm{b}}$ \\
\hline Middle (n, \%) & 1874 & $40(2.1)^{c}$ & $15(1.7)^{\mathrm{b}}$ & $25(2.5)^{c}$ \\
\hline College (n, \%) & 1251 & $5(0.4)^{\mathrm{d}}$ & $2(0.3)^{c}$ & $3(0.6)^{d}$ \\
\hline$P$-value & & $<0.001$ & $<0.001$ & $<0.001$ \\
\hline \multicolumn{5}{|l|}{ Living status: } \\
\hline Living alone (n, \%) & 98 & $9(9.2)$ & $0(0)$ & $9(10.5)$ \\
\hline Not living alone (n, \%) & 3231 & $107(3.3)$ & $30(1.9)$ & $77(4.8)$ \\
\hline P value & & 0.004 & 0.391 & 0.001 \\
\hline \multicolumn{5}{|l|}{ BMI $\left(\mathrm{kg} / \mathrm{m}^{2}\right)$ : } \\
\hline$<18.5(\mathrm{n}, \%)$ & 120 & $3(2.5)$ & $0(0)$ & $3(9.1)$ \\
\hline $18.5-23.9(n, \%)$ & 1310 & $38(2.9)$ & $7(1.5)$ & $31(3.7)$ \\
\hline $24-27(\mathrm{n}, \%)$ & 1444 & $52(3.6)$ & $15(1.8)$ & $37(6.1)$ \\
\hline$\geq 28$ (n, \%) & 581 & $25(4.3)$ & $10(3.0)$ & $15(6.0)$ \\
\hline$P$-value & & 0.277 & 0.442 & 0.099 \\
\hline
\end{tabular}

*Same letters marked in any two subgroups indicate no statistically significant differences. Completely different letters in any two subgroups indicate statistically significant differences.

$\dagger$ Cochran Armitage trend test: Total, $\chi^{2}=300.678, \mathrm{P}<0.001$; Men, $\chi^{2}=66.042, \mathrm{P}<0.001$; Women, $\chi^{2}=204.453, \mathrm{P}<0.001$.

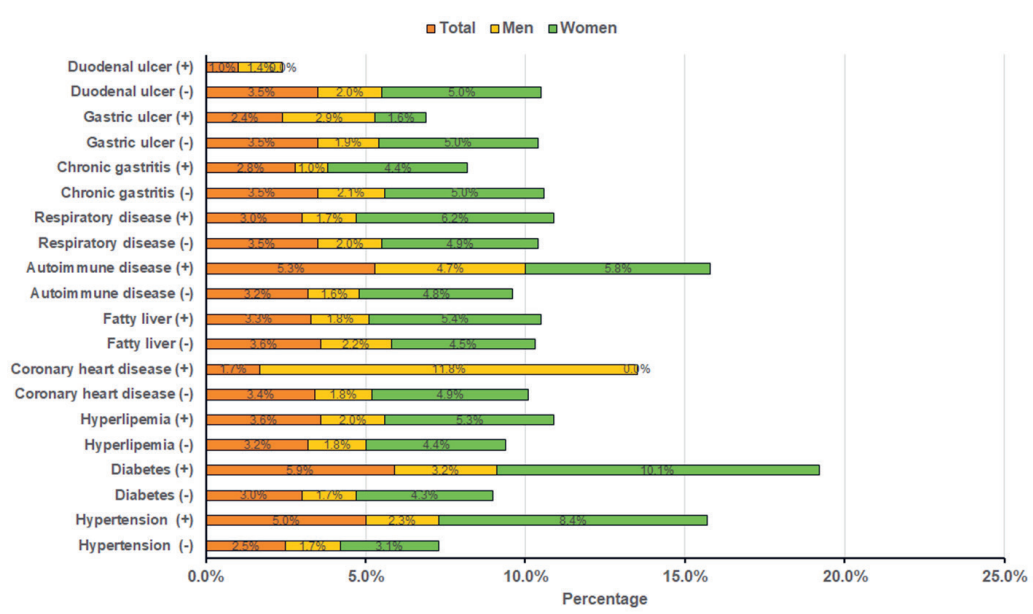

Figure 3. Percentages of cognitive impairment among participants with a history of disease.

participants without these diseases (all $P<0.05$ ). Chi-square tests showed that cognitive impairment was significantly correlated with hypertension $(P<0.001)$ and diabetes $(P<0.001)$ among female participants.

\section{Multivariate logistic regression analysis on determinants for cognitive impairment}

As shown in Figure 4, Panel A, and Figure S1 in the Online Supplementary Document, SHS was significantly correlated with an increased risk of cognitive impairment ( $\mathrm{OR}=2.936,95 \% \mathrm{CI}=1.428-6.033)$ after adjusting for other factors (gender, age, education, per-capita living area, a history of disease). In addition, gender $(P=0.001)$, age $(P=0.001)$ and hypertension $(P=0.034)$ were positively correlated with cognitive impairment, while education and per-capita living space $(P=0.016)$ were negatively correlated with cog- 
Table 3. Prevalence rates of cognitive impairment in behavior-related subgroups.

\begin{tabular}{|c|c|c|c|c|}
\hline BEHAVIORAL FACTORS & No. & Cases & MaLe cASES & FeMALE CASES \\
\hline \multicolumn{5}{|l|}{ Smoke status: } \\
\hline Non-smokers (n, \%) & 2500 & $97(3.9)^{\mathrm{a}}$ & $14(1.8)$ & $83(4.8)$ \\
\hline Smokers (n, \%) & 844 & $16(1.9)^{\mathrm{b}}$ & $13(1.6)$ & $3(8.1)$ \\
\hline Former smokers (n, \%) & 180 & $8(4.4)^{\mathrm{a}, \mathrm{b}}$ & $7(4.0)$ & $1(25.0)$ \\
\hline$P$-value & & 0.018 & 0.114 & 0.115 \\
\hline \multicolumn{5}{|l|}{ Daily smoking amount: } \\
\hline 0 cigarettes per day $(n, \%)$ & 2667 & $106(4.0)^{\mathrm{a}}$ & $22(2.3)$ & $84(4.9)$ \\
\hline $1-10$ cigarettes per day $(n, \%)$ & 315 & $7(2.2)^{a, b}$ & $4(1.4)$ & $3(11.1)$ \\
\hline $11-20$ cigarettes per day $(n, \%)$ & 399 & $6(1.5)^{\mathrm{b}}$ & $6(1.6)$ & $0(0)$ \\
\hline$\geq 21$ cigarettes per day $(n, \%)$ & 143 & $2(1.4)^{a, b}$ & $2(1.4)$ & $0(0)$ \\
\hline$P$-value & & 0.018 & 0.659 & 0.305 \\
\hline \multicolumn{5}{|l|}{ Passive smoking: } \\
\hline Yes (n, \%) & 1061 & $37(3.5)$ & $10(1.9)$ & $27(5.1)$ \\
\hline No $(n, \%)$ & 2463 & $84(3.4)$ & $24(2.0)$ & $60(4.8)$ \\
\hline$P$-value & & 0.909 & 0.928 & 0.846 \\
\hline \multicolumn{5}{|l|}{ Drinking: } \\
\hline Yes (n, \%) & 1106 & $16(1.4)$ & $14(1.4)$ & $2(1.8)$ \\
\hline No $(n, \%)$ & 2343 & $102(4.4)$ & $17(2.4)$ & $85(5.2)$ \\
\hline$P$-value & & $<0.001$ & 0.141 & 0.109 \\
\hline
\end{tabular}

* Same letters marked in any two subgroups indicate no statistically significant differences. Completely different letters in any two subgroups indicate statistically significant differences.
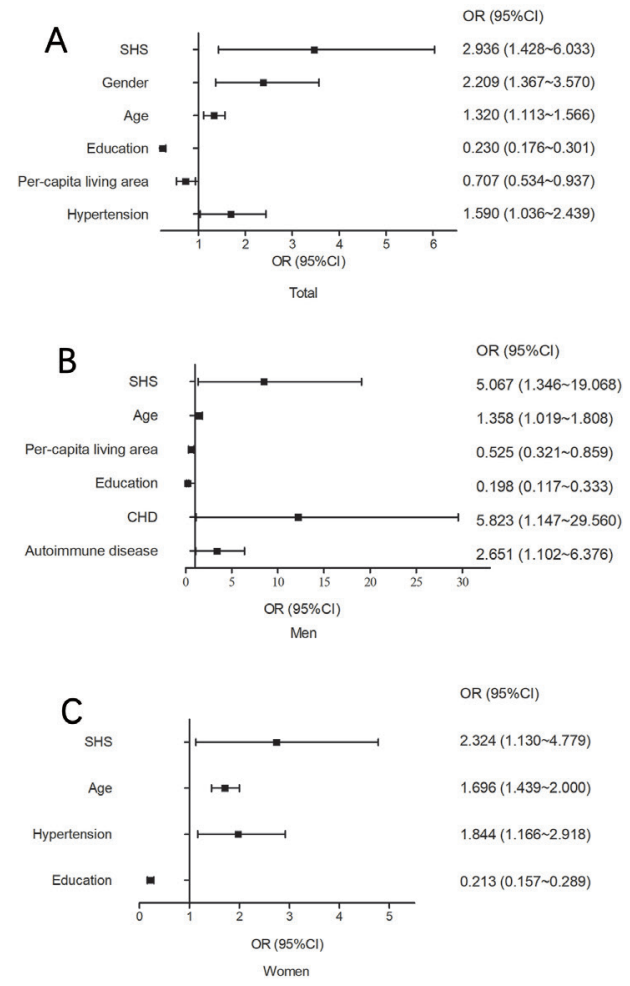

Figure 4. Multivariate logistic regression analysis for cognitive impairment. (A) Among total participants; (B) among men participants; (C) among women participants. SHS - suboptimal health status; CHD - coronary heart disease. nitive impairment. Among the male participants, age $(P=0.037)$, per-capita living space $(P=0.010)$, education level $(P<0.001), C H D(P=0.034)$ and autoimmune disease $(P=0.029)$ were correlated with cognitive impairment (Figure 4, Panel B). While, cognitive impairment was significantly correlated with age $(P<0.001)$, hypertension $(P=0.009)$ and education level $(P<0.001)$ among women (Figure 4, Panel C).

\section{DISCUSSION}

This study has, for the first time, investigated the relationship between SHS and cognitive impairment in middle-aged and older Chinese adults. Our findings indicate that SHS participants tend to have lower cognitive function and SHS might be a risk factor for cognitive impairment. This finding was validated in multivariate logistic regression analysis, which also showed that SHS was significant determinants of cognitive impairment in addition to gender, age, education level, per-capita living space and hypertension.

We also analyzed the prevalence rates of cognitive impairment in subgroups of demographics. Our finding on gender difference was consistent with a published study on a Chinese elderly population, where the prevalence of women (32.9\%) was twice as high as that among men (15.7\%) [26]. These results indicate women experience higher risk for this condition than men $[27,28]$. We also observed the higher prevalence of cognitive impairment in elder participants, validating that the trends of risk go up with increasing age among both men and women $[29,30]$. With regard to the effect of education levels, our study supported that individuals with lower attained education suffered more prevalence of cognitive impairment [31,32]. In terms of living status, we found the occurrence of cognitive impairment might be aggravated by living alone [31]. Interestingly, it is found that people lived in smaller house (measured by the per-capita living space) were exposed to higher risk of cognitive impairment. As is known, living space is related to economic condition or income of residents, which is one of important determinants of cognitive impairment [31,33,34]. 
Behavior-related factors (eg, staying up late) were also observed to be associated with the prevalence of cognitive impairment in this study. It has been found that sleep disorder is not only an important risk factors for cognitive impairment, but also a symptom of neurodegenerative process [35-38]. Among male participants, dietary factors (eg, fried food, pickled food, spicy food and bacon intakes) were strongly associated with cognitive impairment. However, some other previously acknowledged risk factors such as alcohol drinking [39], smoking [40] were found to be non-significant in this study, which might be attributed to the fact that most of participants with cognitive impairment were women (71.9\%). Furthermore, the percentage of cognitive impairment in our study was higher among the participants with hypertension, diabetes and CHD, which has been validated in previous researches [41-43]. These diseases commonly share similar vascular-related risk factors with cognitive impairment, in addition to their underlining contributions to neurodegeneration.

This study identified significant relationship of SHS with cognitive impairment, where oxidative stress might play an important role [44]. Oxidative stress increases the release of a variety of growth factors and molecules, which up-regulate vascular permeability, protein exudation and demyelination of axons, and result in potential disfunction of brain tissue $[45,46]$. In the SHS stage, individuals are exposed to aberrant oxidative stress, which leads to vascular lesions and increases the risk of cardiovascular diseases $[47,48]$. In addition, other researchers found vascular biochemical changes and structural changes in Alzheimer disease (AD) patients [49]. The destruction of blood-brain barrier and neurovascular units is an important pathogenesis of cognitive impairment [50]. Vascular lesion is one of the main causes of dementia in the elderly, suggesting that lesions have a role in cognitive impairment [51-53]. Therefore, SHS might be associated with cognitive impairment by peroxidation stress and vascular lesions.

Dementia have been a common public health burden, which threatens 47 million people worldwide, and this number is expected to increase to 131 million by 2050 [54]. China has the largest number of patients who suffer from dementia that imposes a huge challenge for health care system that has been facing the burden of aging of population [55]. Identification of persons at high risk of dementia and early diagnosis of cognitive impairment, as well as clinical management and care, are still urgently required in China. As far as we know, this is the first study to elucidate the relationship between SHS and cognitive impairment of in Chinese population.

Some limitations of our study should be acknowledged. First, since this study is a cross-sectional study, it is difficult to infer a causality relationship of SHS with cognitive impairment, and the pathophysiological mechanism could not be depicted. Second, MMSE is a simplified scale for cognitive function measurement, and cannot represent clinical evaluation of cognitive impairment or dementia, the accuracy of the results is, more or less, influenced.

In a conclusion, SHS might be a risk factors for cognitive function in a northern Chinese population. Cohort studies are still needed to assess the causal relationship between SHS and cognitive impairment. Early screening of SHS individuals, as well as urgent treatment of SHS is needed to effectively promote the prevention of cognitive impairment.

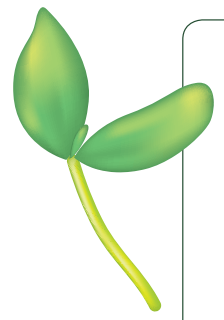

Acknowledgments: We thank the Jidong cognitive impairment cohort study (CICS) participants, without whom this research would not be possible. We thank all investigators for their contributions to data collection. We also thank the teachers and students at schools that participated in this study for their cooperation.

Funding: This study was supported by the National Natural Science Foundation of China $(81973138,81973112$ and 81903401), the Academic Promotion Programme of Shandong First Medical University (2019RC010), the Shandong Province Higher Educational Young and Innovation Technology Supporting Program (2019KJL004), the Young Taishan Scholars Program of Shandong Province of China (No. tsqn20161046), and the Science and Technology Development Project in Taian (2018NS0114).

Authorship contributions: Conceived and designed the experiments: GD HH XZ. Performed the experiments: YW DS DC YD WX HD. Analyzed the data: GD XZ. Contributed reagents/materials/analysis tools: DL YZ HH. Wrote the paper: GD XZ HH.

Competing interests: The authors completed the ICMJE Unified Competing Interest form (available upon request from the corresponding author), and declare no conflicts of interest.

Additional material

Online Supplementary Document 
1 Millán-Calenti JC, Tubio J, Pita-Fernandez S, Rochette S, Lorenzo T, Maseda A. Cognitive impairment as predictor of functional dependence in an elderly sample. Arch Gerontol Geriatr. 2012;54:197-201. Medline:21397345 doi:10.1016/j. archger.2011.02.010

2 Petersen RC, Caracciolo B, Brayne C, Gauthier S, Jelic V, Fratiglioni L. Mild cognitive impairment: a concept in evolution. J Intern Med. 2014;275:214-28. Medline:24605806 doi:10.1111/joim.12190

3 Siu MY, Lee DTF. Effects of tai chi on cognition and instrumental activities of daily living in community dwelling older people with mild cognitive impairment. BMC Geriatr. 2018;18:37. Medline:29394884 doi:10.1186/s12877-018-0720-8

4 Zhou Z, Mao F, Han Y, Fu J, Fang Y. Social engagement and cognitive impairment in older Chinese adults: The mediating role of psychological well-being. J Aging Health. 2019;April 5:898264319839594. [Epub ahead of print] Medline:30947590 doi:10.1177/0898264319839594

5 Wang W, Russell A, Yan Y; Global Health Epidemiology Reference Group (GHERG). Traditional Chinese medicine and new concepts of predictive, preventive and personalized medicine in diagnosis and treatment of suboptimal health. EPMA J. 2014;5:4. Medline:24521056 doi:10.1186/1878-5085-5-4

6 Wang W, Yan Y. Suboptimal health: a new health dimension for translational medicine. Clin Transl Med. 2012;1:28. Medline:23369267 doi:10.1186/2001-1326-1-28

7 Yan Y-X, Liu Y-Q, Li M, Hu P-F, Guo A-M, Yang X-H, et al. Development and evaluation of a questionnaire for measuring suboptimal health status in urban Chinese. J Epidemiol. 2009;19:333-41. Medline:19749497 doi:10.2188/jea. JE20080086

8 Kouvonen A, Oksanen T, Vahtera J, Stafford M, Wilkinson R, Schneider J, et al. Low workplace social capital as a predictor of depression: the Finnish Public Sector Study. Am J Epidemiol. 2008;167:1143-51. Medline:18413361 doi:10.1093/ aje/kwn067

9 Chen SW, Wang PC, Hsin PL, Oates A, Sun IW, Liu SI. Job stress models, depressive disorders and work performance of engineers in microelectronics industry. Int Arch Occup Environ Health. 2011;84:91-103. Medline:20431893 doi:10.1007/ s00420-010-0538-y

10 Grynderup MB, Mors O, Hansen AM, Andersen JH, Bonde JP, Kaergaard A, et al. Work-unit measures of organisational justice and risk of depression-a 2-year cohort study. Occup Environ Med. 2013;70:380-5. Medline:23476045 doi:10.1136/oemed-2012-101000

11 Liang YZ, Chu X, Meng SJ, Zhang J, Wu LJ, Yan YX. Relationship between stress-related psychosocial work factors and suboptimal health among Chinese medical staff: a cross-sectional study. BMJ Open. 2018;8:e018485. Medline:29511008 doi:10.1136/bmjopen-2017-018485

12 Hou H, Feng X, Li Y, Meng Z, Guo D, Wang F, et al. Suboptimal health status and psychological symptoms among Chinese college students: a perspective of predictive, preventive and personalised health. EPMA J. 2018;9:367-77. Medline:30538788 doi:10.1007/s13167-018-0148-4

13 Anstey KJ, Lipnicki DM, Low LF. Cholesterol as a risk factor for dementia and cognitive decline: A systematic review of prospective studies with meta-analysis. Am J Geriatr Psychiatry. 2008;16:343-54. Medline:18448847 doi:10.1097/01. JGP.0000310778.20870.ae

14 Xu WL, Atti AR, Gatz M, Pedersen NL, Johansson B, Fratiglioni L. Midlife overweight and obesity increase latelife dementia risk: a population-based twin study. Neurology. 2011;76:1568-74. Medline:21536637 doi:10.1212/ WNL.Ob013e3182190d09

15 METACOHORTS Consortium. METACOHORTS for the study of vascular disease and its contribution to cognitive decline and neurodegeneration: An initiative of the Joint Programme for Neurodegenerative Disease Research. Alzheimers Dement. 2016;12:1235-49. Medline:27490018 doi:10.1016/j.jalz.2016.06.004

16 Pendlebury ST, Rothwell PM. Prevalence, incidence, and factors associated with pre-stroke and post-stroke dementia: a systematic review and meta-analysis. Lancet Neurol. 2009;8:1006-18. Medline:19782001 doi:10.1016/S14744422(09)70236-4

17 Adua E, Roberts P, Wang W. Incorporation of suboptimal health status as a potential risk assessment for type II diabetes mellitus: a case-control study in a Ghanaian population. EPMA J. 2017;8:345-55. Medline:29209438 doi:10.1007/ s13167-017-0119-1

18 Song D-Y, Wang X-W, Wang S, Ge S-Q, Ding G-Y, Chen X-Y, et al. Jidong cognitive impairment cohort study: objectives, design, and baseline screening. Neural Regen Res. 2020;15:1111-9. Medline:31823892 doi:10.4103/1673-5374.266070

19 Wang Y, Ge S, Yan Y, Wang A, Zhao Z, Yu X, et al. China suboptimal health cohort study: rationale, design and baseline characteristics. J Transl Med. 2016;14:291. Medline:27737677 doi:10.1186/s12967-016-1046-y

20 Folstein MF, Folstein SE, McHugh PR. "Mini-mental state". A practical method for grading the cognitive state of patients for the clinician. J Psychiatr Res. 1975;12:189-98. Medline:1202204 doi:10.1016/0022-3956(75)90026-6

21 Folstein MF, Robins LN, Helzer JE. The Mini-Mental State Examination. Arch Gen Psychiatry. 1983;40:812. Medline:6860082 doi:10.1001/archpsyc.1983.01790060110016

22 Xiu S, Zheng Z, Guan S, Zhang J, Ma J, Chan P. Serum uric acid and impaired cognitive function in community-dwelling elderly in Beijing. Neurosci Lett. 2017;637:182-7. Medline:27890742 doi:10.1016/j.neulet.2016.11.013

23 Hou Q, Guan Y, Yu W, Liu X, Wu L, Xiao M, et al. Associations between obesity and cognitive impairment in the Chinese elderly: an observational study. Clin Interv Aging. 2019;14:367-73. Medline:30863030 doi:10.2147/CIA.S192050

24 Yan YX, Liu YQ, Li M, Hu PF, Guo AM, Yang XH, et al. Development and evaluation of a questionnaire for measuring suboptimal health status in urban Chinese. J Epidemiol. 2009;19:333-41. Medline:19749497 doi:10.2188/jea. JE20080086 
25 Ge S, Xu X, Zhang J, Hou H, Wang H, Liu D, et al. Suboptimal health status as an independent risk factor for type 2 diabetes mellitus in a community-based cohort: the China suboptimal health cohort study. EPMA J. 2019;10:65-72. Medline:30984315 doi:10.1007/s13167-019-0159-9

26 Miyawaki CE, Liu M. Gender differences in cognitive impairment among the old and the oldest-old in China. Geriatr Gerontol Int. 2019;19:586-92. Medline:30957346 doi:10.1111/ggi.13666

27 Zhou Z, Mao F, Zhang W, Towne SD Jr, Wang P, Fang Y. The association between loneliness and cognitive impairment among older men and women in China: A nationwide longitudinal study. Int J Environ Res Public Health. 2019;16:E2877. Medline:31408955 doi:10.3390/ijerph16162877

28 Tang F, Chi I, Dong X. Sex differences in the prevalence and incidence of cognitive impairment: Does immigration matter? J Am Geriatr Soc. 2019;67 S3:S513-S518. Medline:31403204 doi:10.1111/jgs.15728

29 Wong MYZ, Tan CS, Venketasubramanian N, Chen C, Kamran Ikram M, Cheng CY, et al. Prevalence and risk factors for cognitive impairment and dementia in Indians: A multiethnic perspective from a Singaporean Study. J Alzheimers Dis. 2019;71:341-51. Medline:31381520 doi:10.3233/JAD-190610

30 Cooper C, Sommerlad A, Lyketsos CG, Livingston G. Modifiable predictors of dementia in mild cognitive impairment: a systematic review and meta-analysis. Am J Psychiatry. 2015;172:323-34. Medline:25698435 doi:10.1176/appi. ajp.2014.14070878

31 Zhang Q, Wu Y, Han T, Liu E. Changes in cognitive function and risk factors for cognitive impairment of the elderly in China: 2005-2014. Int J Environ Res Public Health. 2019;16:2847. Medline:31404951 doi:10.3390/ijerph16162847

32 Kramer M, German PS, Anthony JC, Von Korff M, Skinner EA. Patterns of mental disorders among the elderly residents of eastern Baltimore. J Am Geriatr Soc. 1985;33:236-45. Medline:3989184 doi:10.1111/j.1532-5415.1985.tb07110.x

33 Ozakbas S, Turkoglu R, Tamam Y, Terzi M, Taskapilioglu O, Yucesan C, et al. Prevalence of and risk factors for cognitive impairment in patients with relapsing-remitting multiple sclerosis: Multi-center, controlled trial. Mult Scler Relat Disord. 2018;22:70-6. Medline:29605801 doi:10.1016/j.msard.2018.03.009

34 Liang X, Chen Z, Dong X, Zhao Q, Guo Q, Zheng L, et al. Mental work demands and late-life cognitive impairment: Results from the Shanghai Aging Study. J Aging Health. 2019;31:883-98. Medline:29661060 doi:10.1177/0898264318765034

35 Song QF, Liu XX, Hu WN, Han XC, Zhou WH, Lu AD, et al. Night sleep duration and risk of cognitive impairment in a Chinese Population: A cross-sectional study. Biomed Environ Sci. 2017;30:749-57. Medline:29122095

36 Fortier-Brochu E, Beaulieu-Bonneau S, Ivers H, Morin CM. Insomnia and daytime cognitive performance: a meta-analysis. Sleep Med Rev. 2012;16:83-94. Medline:21636297 doi:10.1016/j.smrv.2011.03.008

37 Gadie A, Shafto M, Leng Y, Kievit RA. How are age-related differences in sleep quality associated with health outcomes? An epidemiological investigation in a UK cohort of 2406 adults. BMJ Open. 2017;7:e014920. Medline:28760786 doi:10.1136/bmjopen-2016-014920

38 Palmer K, Mitolo M, Burgio F, Meneghello F, Venneri A. Sleep disturbance in mild cognitive impairment and association with cognitive functioning. A case-control study. Front Aging Neurosci. 2018;10:360. Medline:30473661 doi:10.3389/ fnagi.2018.00360

39 Woods AJ, Porges EC, Bryant VE, Seider T, Gongvatana A, Kahler CW, et al. Current heavy alcohol consumption is associated with greater cognitive impairment in older adults. Alcohol Clin Exp Res. 2016;40:2435-44. Medline:27658235 doi:10.1111/acer.13211

40 Brayne C. Smoking and the brain. BMJ. 2000;320:1087-8. Medline:10775202 doi:10.1136/bmj.320.7242.1087

$41 \mathrm{Li} \mathrm{W}$, Sun L, Li G, Xiao S. Prevalence, influence factors and cognitive characteristics of mild cognitive impairment in type 2 diabetes mellitus. Front Aging Neurosci. 2019;11:180. Medline:31417393 doi:10.3389/fnagi.2019.00180

42 Keyimu K, Zhou XH, Miao HJ, Zou T. Mild cognitive impairment risk factor survey of the Xinjiang Uyghur and Han elderly. Int J Clin Exp Med. 2015;8:13891-900. Medline:26550345

43 Xiu S, Liao Q, Sun L, Chan P. Risk factors for cognitive impairment in older people with diabetes: a community-based study. Ther Adv Endocrinol Metab. 2019;10:2042018819836640. Medline:31156800 doi:10.1177/2042018819836640

44 Rosenberg GA. Inflammation and white matter damage in vascular cognitive impairment. Stroke. 2009;40(3 Suppl):S20-3. Medline:19064797 doi:10.1161/STROKEAHA.108.533133

45 Cammer W, Bloom BR, Norton WT, Gordon S. Degradation of basic protein in myelin by neutral proteases secreted by stimulated macrophages: a possible mechanism of inflammatory demyelination. Proc Natl Acad Sci U S A. 1978;75:15548. Medline:148651 doi:10.1073/pnas.75.3.1554

46 da Rosa PM, Meira LAM, Souza DO, Bobermin LD, Quincozes-Santos A, Leite MC. High-glucose medium induces cellular differentiation and changes in metabolic functionality of oligodendroglia. Mol Biol Rep. 2019;46: 4817-26. Medline:31270757 doi:10.1007/s11033-019-04930-4

47 Feng L, Chong MS, Lim WS, Lee TS, Collinson SL, Yap P, et al. Metabolic syndrome and amnestic mild cognitive impairment: Singapore Longitudinal Ageing Study-2 findings. J Alzheimers Dis. 2013;34:649-57. Medline:23246920 doi:10.3233/JAD-121885

48 Sun N, Xi Y, Zhu Z, Yin H, Tao Q, Wang H, et al. Effects of anxiety and depression on arterial elasticity of subjects with suboptimal physical health. Clin Cardiol. 2015;38:614-20. Medline:26509854 doi:10.1002/clc.22455

49 Stopa EG, Butala P, Salloway S, Johanson CE, Gonzalez L, Tavares R, et al. Cerebral cortical arteriolar angiopathy, vascular beta-amyloid, smooth muscle actin, Braak stage, and APOE genotype. Stroke. 2008;39:814-21. Medline:18258839 doi:10.1161/STROKEAHA.107.493429

50 Jellinger KA. The enigma of vascular cognitive disorder and vascular dementia. Acta Neuropathol. 2007;113:349-88. Medline:17285295 doi:10.1007/s00401-006-0185-2 
51 Jellinger KA. Prevalence and impact of cerebrovascular lesions in Alzheimer and Lewy body diseases. Neurodegener Dis. 2010;7:112-5. Medline:20173339 doi:10.1159/000285518

52 Schneider JA, Wilson RS, Cochran EJ, Bienias JL, Arnold SE, Evans DA, et al. Relation of cerebral infarctions to dementia and cognitive function in older persons. Neurology. 2003;60:1082-8. doi:10.1212/01.WNL.0000055863.87435.B2. Medline: 12682310

53 Schneider JA, Arvanitakis Z, Bang W, Bennett DA. Mixed brain pathologies account for most dementia cases in communitydwelling older persons. Neurology. 2007;69:2197-204. doi:10.1212/01.wnl.0000271090.28148.24. Medline:17568013

54 Arvanitakis Z, Shah RC, Bennett DA. Diagnosis and management of dementia. JAMA. 2019;322:1589-99. doi:10.1001/ jama.2019.4782. Medline:31638686

55 Jia L, Quan M, Fu Y, Zhao T, Li Y, Wei C, et al. Dementia in China: epidemiology, clinical management, and research advances. Lancet Neurol. 2020;19:81-92. Medline:31494009 doi:10.1016/S1474-4422(19)30290-X 